九州大学学術情報リポジトリ

Kyushu University Institutional Repository

The Influence of Genotype on the Production of Lent inula edodes Grown on Sawdust-Based Substrate

Ohga, Shoji

Research Institute of Kyushu University Forests, Kyushu University

https://doi.org/10.5109/24247

出版情報: 九州大学大学院農学研究院紀要. 43 (1/2)，pp. 39-45，1998-11. Kyushu University バージョン：

権利関係 : 


\title{
The Influence of Genotype on the Production of Lentinula edodes Grown on Sawdust-Based Substrate
}

\author{
Shoj̣i Ohga \\ Research Institute of Kyushu University Forests, Kyushu Lniversity, \\ Sasaguri Fukuoka 811-2415, Japan \\ (Received June 8, 1998 and accepted August 7, 1998)
}

\begin{abstract}
The effect of genotype on shiitake mushroom production on sawdust-bascd substrate was studied. There was significant difference in yield between these genotypes. Characteristics such as fruiting competence, sporophore morphology and mushroom yield varied considerably among the strains. Strains KS -10 and KS-9 belonging to wide-range genotypes produced high yields, strains KS-24 and KS-6 belonging to the cold-weather genotype fruited with high quality mushrooms. Production of shiitake mushroom on the sawdust-based substrate in the out door conditions resulted in low yields.
\end{abstract}

\section{INTRODUCTION}

Shitake (Lentinula edodes (Berk.) Pegler) is the second most economically important of the cultivated mushrooms and is the major mushroom species grown on wood. It is cultivated either on oak logs or on sawdust-based substrate within plastic bags. Cultivation of shiitake on logs mainly in outdoor conditions has become especially strongly established in Japan. Recently, there has also been an increase of interest in growing this mushroom on sawdust-based substrates. The main advantage of the sawdust based substrate method is the shorter production cycle, which occupies between 6 to 12 mouths, compared to the log cultivation method that can take as long as 3 to 4 years. The sawdust-based substrate method also makes it possible to cultivate shiitake throughout the year.

Considerable research efforts are now being directed towards the elucidation of factors contributing to yield and size variations in the sawdust-based cultivation method (Han et al., 1981; Leatham, 1983; Diehle and Royse, 1986; Royse and Bahler, 1986; Przybylowicz and Donoghue, 1990). Various factors have been reported to be implicated to both the vegetative development and fructification in shiitake (Ohga, 1992; Ohga el al., 1992). Further knowledge is necessary to show how different genotypes interact with sawdust-based substrate in regard to toial production and the qualiiy of mushirooms thai can be produced.

The study reported here was conducted to determined the effects of the various different genotypes on the growth and fructification of $L$. edodes.

\section{MATERIALS AND METHODS}

\section{Strains}

Twelve strains belong to 3 different fruiting types were examined in this study. These were KS-5, KS-9, KS-10 and KS-46 (Wide-range), KS-43, KS-53, KS-58 and 
KS-60 (Warm-weather), and KS-6, KS-22, KS-24 and KS-50 (Cold-weather). All of these strains were maintained in the Kyushu University Forests culture collection. Cultures were maintained on potato dextrose agar in sterile $9 \mathrm{~cm}$ Petri dishes.

\section{Culture}

The substrate consisted of Quercus mongolica sawdust supplemented with wheat bran $10 \%$, rice bran $10 \%$ and bean-curd refuse $10 \%$. Moisture content was adjusted to $62 \%$ with water. The mixture was packed in polypropylene bags $(1.3 \mathrm{~kg}, \phi 14 \times 12 \mathrm{~cm})$, and was sterilized in the autoclaving for $1 \mathrm{~h}$. Inoculation of the substrate with spawn $(15 \mathrm{~g})$ was done in aseptic conditions. The culture bags were kept in the incubation room at $17-20^{\circ} \mathrm{C}$ in the dark. After the mycelia fully colonized the substrate, the bags were exposed to dim light of 100 lux. The maturation stage for the mycelium was reached within 3 months from inoculation. The plastic bags were completely removed for the mushroom production stage. The colonized mature cultures were then transferred to a production room. Temperature was maintained at $15^{\circ} \mathrm{C}$ and relative humidity was kept at $90-100 \%$ by automatic misting. Light intensity was maintained at $500-1,000$ lux by fluorescent lamps in cycle of $12 \mathrm{~h}$ light and dark per day. Some of colonized cultures were placed directly on the ground outdoors. The weather conditions of the experimental period in October 1996 at Ashoro, Hokkaido, Kyushu University Forests, Hokkaido Experimental Station were as follows: average of max. temperature was $15^{\circ} \mathrm{C}$, average of min. temperature was $3^{\circ} \mathrm{C}$, and rainfall was $36 \mathrm{~mm}$. Fruit bodies were picked when the veil had broken and the gills were fully exposed. All fruit bodies were counted and weighed. Numbers of cultures tested was 50 per strain in indoor production house and for outdoor field conditions, respectively. Total numbers of cultures tested was 1,200.

\section{RESULTS AND DISCUSSION}

\section{Fruit body yield}

Variation for fruiting capacity was found among tested strains (Fig. 1). The strains $\mathrm{KS}-9$ and KS-10 belonging to the wide-range fruiting type produced high yields. KS- 53 , a warm-weather type and KS-50, a cold-weather type gave quite low yield in the condition used in this study. The culture conditions used here for evaluation of the genotypes may be more suitable for the wide-range type strains such as KS-10, KS-9 and KS-5. Warm-weather genotype strains showed rapid mycelial growth and produced a dense white mycelial mat on the substrate surface in the early stages of colonisation. Browning oxidation products appeared quite early, before day 30. A brown liquid appeared in the plastic bags. The incubation period for complete vegetative growth to these warm-weather strains may be less than 90 days. For the cold-weather strains, the incubation time was not sufficient for fruiting initiation. The yield of the first flush was low, especially in the strains KS-24 and KS-50.

\section{Fruit body morphology}

Second flush yield and the morphology of sporophores are shown in Fig. 2. Cold-weather strains gave a high yield in the 2nd flush. This suggests that the cold-weather strain cultures reached a suitable degree of culture maturity by day 110 . 


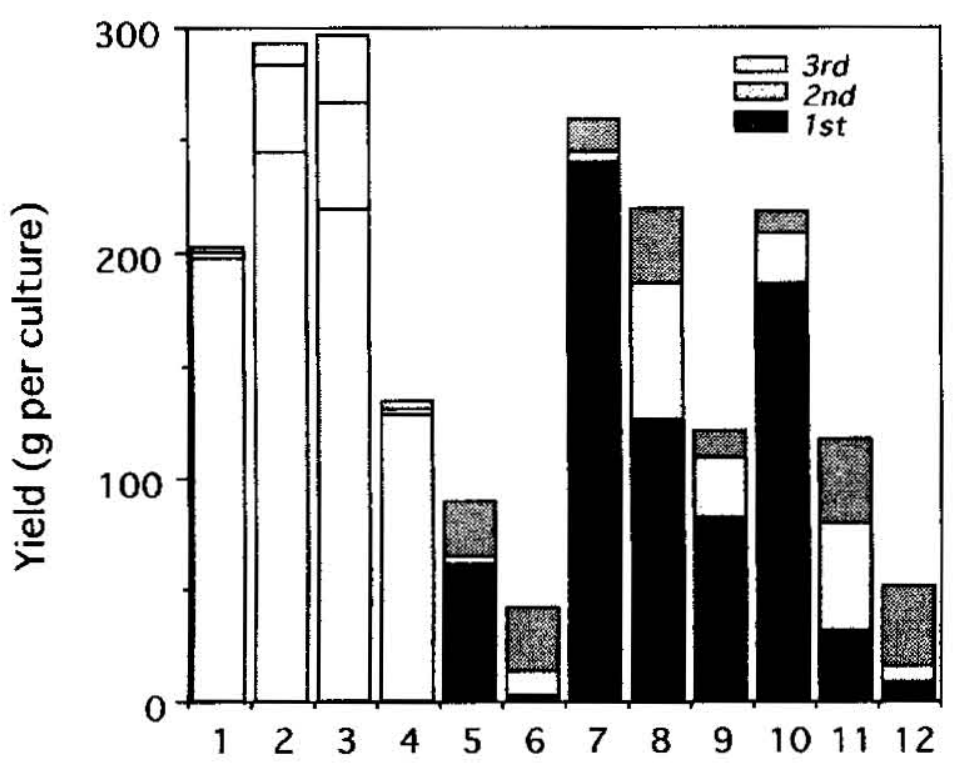

\title{
Spawn variety
}

\author{
Wide - Renge $\quad: 1:$ KS - $5, \quad 2:$ KS - $9, \quad 3:$ KS - 10, 4: KS - 46 \\ Warm - Weather : 5: KS - 43, 6: KS - 53, 7: KS - 58, 8: KS - 60 \\ Cold-Weather : 9: KS - 6, 10:KS-22, 11:KS-24, 12:KS - 50
}

Fig. 1. Fruit body yicld in various genotype of $L$. edodes on sawdust-based substrate.

Two strains, KS-6 and $\mathrm{KS}-24$, belonging to the cold-weather type produced large high quality fruit bodies at this stage.

\section{Fruiting environment}

Fruit body yield in different environment conditions is shown in Fig. 3. Reduction of fruit body yield was found for cultures transferred to outdoor conditions. Crop yield in the outdoor conditions was lower than the indoor controlled conditions in all of the tested strains. The strains, KS-43 and KS-53, belonging to warm-weather genotypes and KS-50 belonging to the cold-weather genotype did not fruited in the weather conditions of the outdoor experimental period. These 3 strains also showed quite low yield in the growing house. The reason for this low yield may be insufficient culture maturity in these strains when grown on the substrate. 

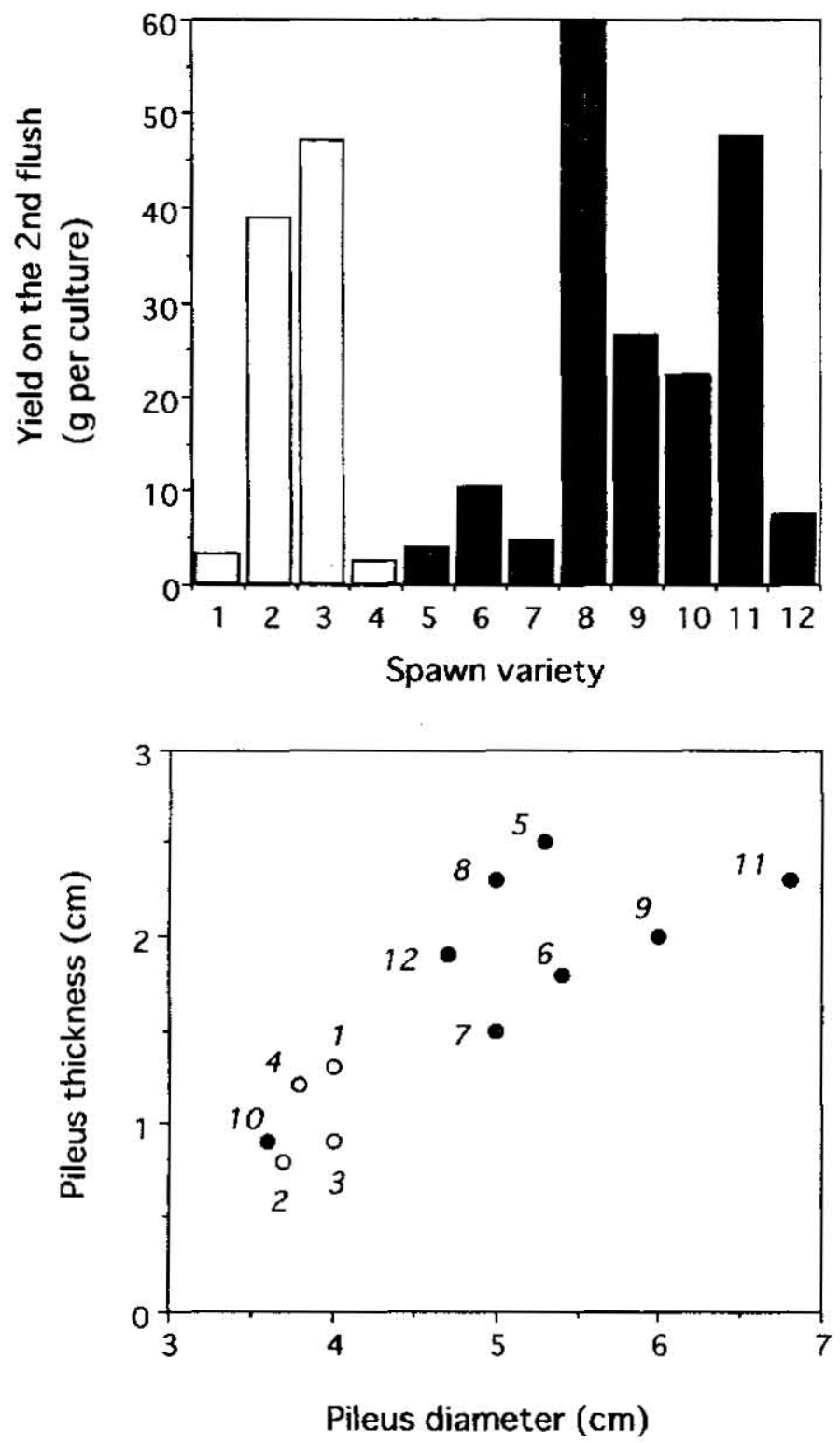

Fig. 2. Yield and size of sporophores in 2nd flush of $L$. edodes on sawdust-based substrate.

Number of spawis are same as in Fig. 1. 


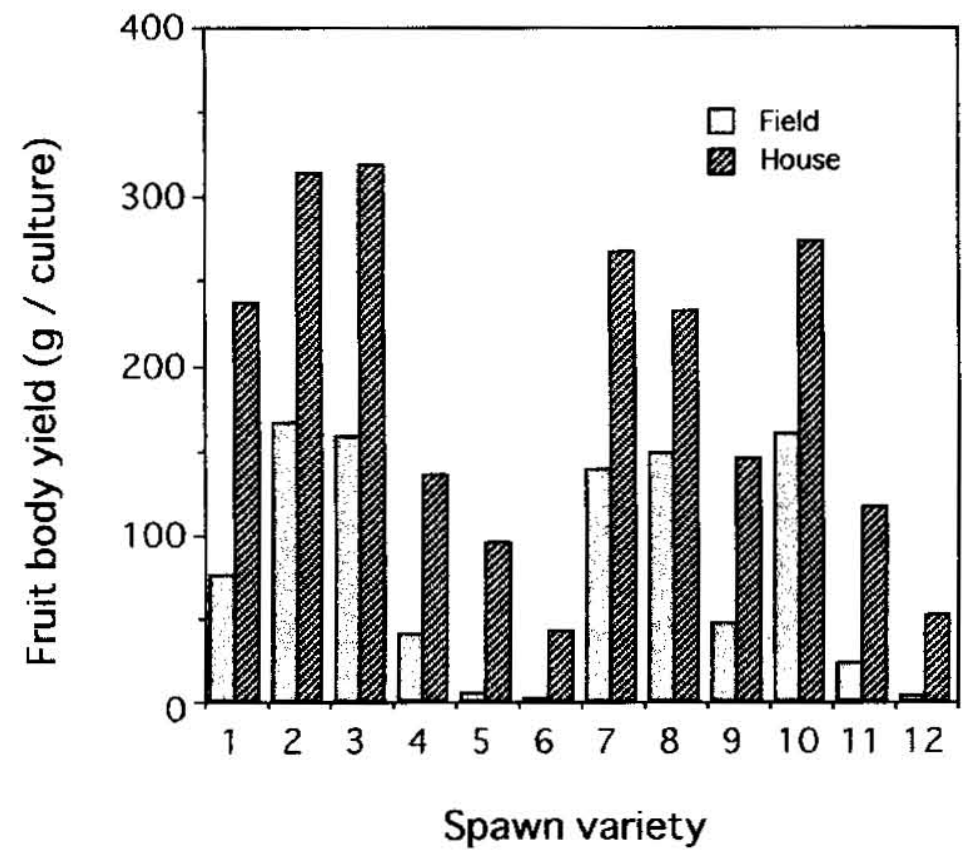

Fig. 3. Fruit body yieldy of $L$. edodes on sawdust-based substrate in different circumstance.

Number of spawns are same as in Fig. 1.

\section{Flushing pattern}

Fruiting patterns for numbers and yield from the production house and the outdoor field conditions are shown in Fig. 4. Numbers of fruit body was between 1 to 6 per 1 substrate in the production house cultivation, variation of flush number was found outdoor cultivation. Fruit bodies yield showed the same pattern. The range of fruit body weight was between 55 to $98 \mathrm{~g}$ per 1 substrate.

\section{ACKNOWLEDGMENT}

This work was supported in part by the financial aid from the Scientific Research Fund (No. 09660188) of the Japanese Ministry of Education, Science, Sports and Culture. 

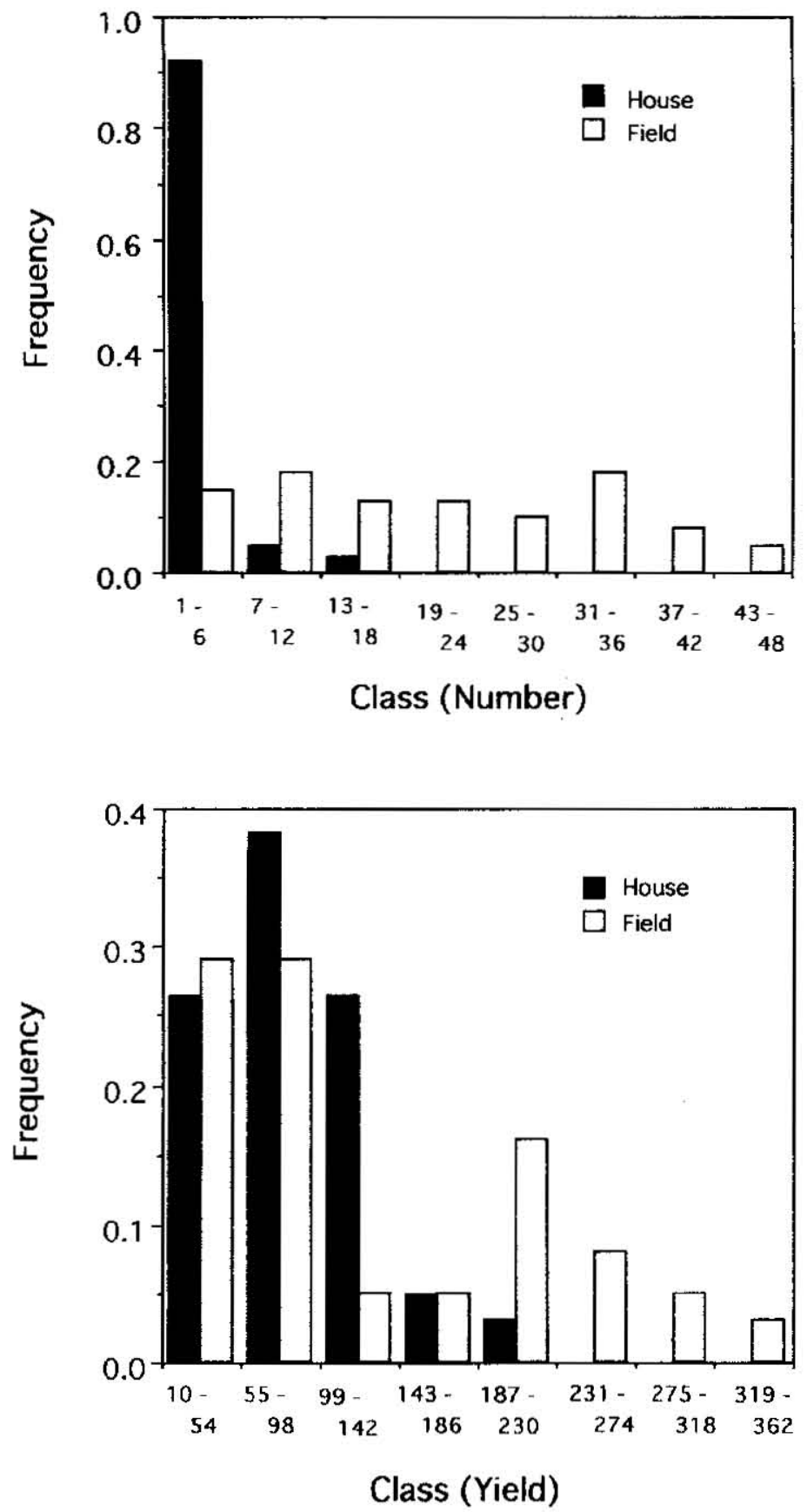

Fig. 4. Histograms of sporophores quality of $L$. edodes growing on sawdust-based substrate in different circumstance. 


\section{REFERENCES}

Diehle, D. A. and D. J. Royse 1986 Shitake cultivation on sawdust: evaluation of selected genotypes for biological cfficiency and mushroom size. Mycologia, 78: 929-933

Han, Y. H., W. T. Leng, L. C. Chen and S. Cherig 1981 Physiology and ecology of Lentinus edodes (Berk.) Sing. Mush. Sci, 11: 623-658

Leatham, G. F. 1983 A chemically defined medium for the fruiting of Lentimus edodes. Mycologia, 75: 905-908

Ohga, S, 1992 Adaptability of Lentinus edodes strains to a sawdust based cultivating procedure. Mokuzai Gakkaishi, 38: 301-309

Ohıga, S., F. V. Roozendacl, M. Aspinwall and M. Miwa 1992 Yield and size response of the shitake mushroorn, Lentinus edodes, depending on incubation time on sawdust-based culture. Trans. Mycol. Soc. Japan, 33: 349-357

Przybylowicz, P. and J. Donoghue 1990 Shiitake Growers Handbook. Kendall/Hunt Pub. Corn., Iowa (USA)

Royse, D. I. and C. C. Bahler 1986 Effect of genotypc, spawn run time, and substrate formation on biological efficicncy of shiitake. Appl. Environ. Microbiol., 52: 1425-1427 